THEORY AND METHODS

\title{
Block observations of neighbourhood physical disorder are associated with neighbourhood crime, firearm injuries and deaths, and teen births
}

\author{
Evelyn Wei, Alison Hipwell, Dustin Pardini, Jennifer M Beyers, Rolf Loeber
}

J Epidemiol Community Health 2005;59:904-908. doi: 10.1136/jech.2004.027060

See end of article for authors' affiliations

......................

Correspondence to: Professor R Loeber Department of Psychiatry, Western Psychiatric Institute and Clinic, University of Pittsburgh Medical Center, 3811 O'Hara Street, Pittsburgh PA 15213, USA; loeberr@ upmc.edu

Accepted for publication 12 June 2005
Study objective: To provide reliability information for a brief observational measure of physical disorder and determine its relation with neighbourhood level crime and health variables after controlling for census based measures of concentrated poverty and minority concentration.

Design: Psychometric analysis of block observation data comprising a brief measure of neighbourhood physical disorder, and cross sectional analysis of neighbourhood physical disorder, neighbourhood crime and birth statistics, and neighbourhood level poverty and minority concentration.

Setting: Pittsburgh, Pennsylvania, US (2000 population $=334$ 563).

Participants: Pittsburgh neighbourhoods $(n=82)$ and their residents (as reflected in neighbourhood level statistics).

Main results: The physical disorder index showed adequate reliability and validity and was associated significantly with rates of crime, firearm injuries and homicides, and teen births, while controlling for concentrated poverty and minority population.

Conclusions: This brief measure of neighbourhood physical disorder may help increase our understanding of how community level factors reflect health and crime outcomes.
E cological studies relating variability in area characteristics to crime rates, and contextual studies linking community processes to individual level crime have greatly increased our understanding of how disadvantaged neighbourhoods impart risk on residents. There is considerable evidence that structural neighbourhood characteristics such as concentrated disadvantage and residential instability are related to lower levels of neighbourhood social control (that is, less ability to maintain an orderly environment) and collective efficacy (that is, less ability to realise collective goals), which are in turn related to increased risk for crime and victimisation. ${ }^{12}$ Such characteristics are partially or fully mediated by community processes (for example, social control, collective efficacy, social capital) in their association with adolescent behaviour problems and mental health. ${ }^{34}$

Much of the research examining the structural characteristics of US neighbourhoods has relied upon administrative data derived from the decennial census. ${ }^{5}$ However, experts in the developing field of "ecometrics" (the science of measuring ecological settings) emphasise the importance of also using systematic observations to gather complete information about neighbourhoods. ${ }^{67}$ Physical signs of neighbourhood disorder, such as litter, graffiti, and abandoned cars are of particular theoretical interest because they are considered to be direct reflections of residents' inability or unwillingness to collectively prevent, manage, or improve undesired neighbourhood activity. ${ }^{7}$ Signs of disorder also reflect neighbourhood deterioration and external agencies' failure to tackle these problems, resulting in disinvestment and out-migration. $^{89}$

In a pioneering study, Sampson and Raudenbush ${ }^{8}$ showed that the relation between systematic social observations of neighbourhood disorder with violent victimisation and crime was explained by lower collective efficacy, even after accounting for census based neighbourhood structural characteristics. The procedure used to obtain systematic ratings of disorder included both "live" observations and observations coded from videotape. The investigators acknowledge that the costs of this methodology for large scale research are substantial. ${ }^{10}$ This paper replicates and extends these findings by examining the psychometric properties of a shorter form of their observation based measure of neighbourhood physical disorder and investigating its associations with neighbourhood level crime and public health. Epidemiologists have long been interested in the public health impact of "place" as a means of understanding socioeconomic disparities in health. ${ }^{11}{ }^{12}$ Recent research has shown that neighbourhood disadvantage predicts a diversity of poorer health outcomes, such as injury, mortality, ${ }^{13}$ and low weight births ${ }^{14}$ and neighbourhood physical disorder, specifically, has been shown to predict gonorrhoea and premature mortality. ${ }^{14} 15$

The specific aims of this paper are to: (1) establish the inter-rater reliability, internal consistency, and convergent validity of a brief index of neighbourhood physical disorder based on systematic block observations, and (2) compare the utility of this index to that of census based neighbourhood poverty for predicting rates of crime, firearm injuries and homicide, teenage births, and low weight births. In addition to elucidating the substantive associations between physical disorder and neighbourhood level crime and health, the last aim allows us to evaluate whether or not an observed measure of neighbourhood offers a more complete understanding of disadvantaged neighbourhood settings than administrative measures, particularly in relation to social impact. We also control for minority concentration to establish whether the results hold independently of social and financial disadvantages associated with ethnicity.

Abbreviations: ICC, intraclass correlation; PDI, physical disorder index *Evelyn Wei has died since this work was undertaken. 
Table 1 Descriptive statistics and correlations with neighbourhood physical disorder $(n=82)$

\begin{tabular}{|c|c|c|c|c|c|}
\hline & Mean & SD & Range & $\begin{array}{l}\text { Correlation with } \\
\text { physical disorder }\end{array}$ & p Value \\
\hline $\begin{array}{l}\text { Physical disorder } \\
\text { Census } 2000 \text { data }\end{array}$ & 1.99 & 0.79 & $0-3.88$ & & \\
\hline Family poverty & 18.19 & 15.39 & $0-72.10$ & 0.49 & $<0.001$ \\
\hline Vacant households & 13.43 & 8.80 & $.86-42.71$ & 0.63 & $<0.001$ \\
\hline Minority concentration & 35.04 & 34.38 & $.22-96.96$ & 0.47 & $<0.001$ \\
\hline \multicolumn{6}{|l|}{ Crime* $^{*}$} \\
\hline 1999 Total crimes $\dagger$ & 155.73 & 111.42 & $23.95-626.61$ & 0.56 & $<0.001$ \\
\hline 2000 Total crimes $\dagger$ & 142.72 & 87.84 & $26.12-478.30$ & 0.58 & $<0.001$ \\
\hline \multicolumn{6}{|l|}{ Firearm injuries $\ddagger$} \\
\hline 1999 Any firearm injuries/homicides & 0.66 & 0.48 & $0-1$ & 0.24 & 0.028 \\
\hline 2000 Any firearm injuries/homicides & 0.65 & 0.48 & $0-1$ & 0.40 & $<0.001$ \\
\hline 1999 Any firearm injuries & 0.61 & 0.49 & $0-1$ & 0.22 & 0.047 \\
\hline 2000 Any firearm injuries & 0.61 & 0.49 & $0-1$ & 0.34 & 0.002 \\
\hline 1999 Any firearm homicides & 0.23 & 0.42 & $0-1$ & 0.46 & $<0.001$ \\
\hline 2000 Any firearm homicides & 0.26 & 0.44 & $0-1$ & 0.33 & 0.001 \\
\hline \multicolumn{6}{|l|}{ Birth statistics } \\
\hline 1999 Teen births§ & 50.95 & 65.91 & $0-500.00$ & 0.41 & $<0.001$ \\
\hline 2000 Teen births§ & 46.58 & 41.66 & $0-230.77$ & 0.58 & $<0.001$ \\
\hline 1999 Low birth weight (of all births) & 10.13 & 7.70 & $0-34.15$ & 0.23 & 0.035 \\
\hline 2000 Low birth weight (of all births) & 10.50 & 7.84 & $0-40.00$ & 0.27 & 0.016 \\
\hline
\end{tabular}

\section{METHODS}

This study was conducted in 1998-2000 in the City of Pittsburgh, Allegheny County, Pennsylvania. According to the 2000 census, Pittsburgh has 334563 residents, a median household income of $\$ 28588$, a $10.7 \%$ unemployment rate among adults in the labour force, and has seen a steady decline in population over the past 50 years $(10 \%$ from 1990 to 2000). Most residents are white (67.6\%) or African American $(27.1 \%) ; 1.3 \%$ is Hispanic or Latino. The city consists of 91 neighbourhoods that are known by name to residents.

\section{Measurement of physical disorder}

Observations of street face blocks took place from 1998 to 2000 while households were being enumerated to identify participants for a population based longitudinal study of the development of problem behaviours in girls. ${ }^{16}$ The Institutional Review Board at the University of Pittsburgh approved all protocols for the large scale study of which the block observations were a part. Street blocks were selected for enumeration from a citywide list of addresses obtained from the department of city planning, the US Postal Service, and the 911 database. In the 23 neighbourhoods where at least $25 \%$ lived below the poverty level, ${ }^{17}$ all blocks were enumerated, and in 66 of the other neighbourhoods $50 \%$ of the blocks were selected randomly for enumeration. Two neighbourhoods were not sampled: one because of the low density of residential dwellings, and one, newly formed, because of the lack of an address database. In all, 103238 households were enumerated and block observation logs (described below) were filled out for 6203 block faces in 89 neighbourhoods.

The neighbourhood physical disorder index was based on data from the block observation log, a shortened version of an observational measure developed by Sampson and Raudenbush. ${ }^{8}$ The log prompted observers to rate particular street patterns and conditions, volume of traffic, land use, and physical disorder such as graffiti and litter on the pavements. The enumerators received training on completing the $\log$ and were provided with manuals containing general instructions and definitions. The physical disorder index (PDI) consisted of the sum of five items from the block observation log: the presence (1) or absence (0) of graffiti, beer or liquor cans or bottles, cigarette butts, litter or broken glass, and abandoned cars. Condoms, needles or drug paraphernalia, and broken automobile glass were not included because they occurred at a very low frequency. The index was calculated at the neighbourhood level by averaging the scores for blocks within each neighbourhood.

Seven of the 89 enumerated neighbourhoods were excluded from analyses because fewer than 10 blocks had been enumerated or because its total population was below 300. Block observations with complete data provided the information for the PDI $(n=6107)$. For blocks that were rated by multiple enumerators $(n=437)$, one rating was randomly selected for inclusion in the analyses. Thus, 82 neighbourhoods comprised of 5670 blocks served as the units of analysis. Across these neighbourhoods, graffiti was observed on $27.8 \%$ of the blocks, beer or liquor cans or bottles in $32.2 \%$, cigarette butts in $70.4 \%$, litter or broken glass in $63.7 \%$, and abandoned cars in $12.7 \%$.

\section{Inter-rater reliability}

To collect data for establishing inter-rater reliability, the first and fourth authors independently re-visited a random 5\% $(\mathrm{n}=311)$ of the enumerated blocks, stratified by neighbourhood. When possible, these data were collected at times similar to the corresponding original observations (that is, daytime compared with evening, weekday compared with weekend).

\section{Other neighbourhood characteristics}

All other neighbourhood level characteristics were obtained from various public data sources. Percentage of vacant homes, minority concentration (that is, percentage of African American residents), and percentage of families living below the poverty level were based on data from the 2000 census. ${ }^{18} 19$ To convert census tract data to the neighbourhood level, percentages were averaged across neighbourhoods consisting of more than one census tract.

Neighbourhood crime for 1999 and 2000 was indexed by the total number of crimes per 1000 neighbourhood residents. $^{2021}$ Firearm related injuries and homicides for 1999 and 2000, based on incidents reported by the city coroner's office and the trauma centres of the four major local hospitals, correspond to the neighbourhood of the victim's residence. ${ }^{22} 23$ Because most neighbourhoods had no, or few, firearm related injuries/homicides, these variables 
Table 2 Hierarchical logistic regression of firearm injury/homicides in the year 2000 by neighbourhood physical disorder $(n=82)$

\begin{tabular}{|c|c|c|c|c|}
\hline & & B & SE & Odds ratio $(95 \% \mathrm{Cl})$ \\
\hline \multicolumn{5}{|c|}{ Any firearm injury/homicide } \\
\hline \multirow[t]{2}{*}{ Step 1} & Minority concentration & 0.025 & 0.012 & $1.026(1.001,1.051)$ \\
\hline & Family poverty & 0.032 & 0.032 & $1.033(0.970,1.099)$ \\
\hline \multirow[t]{3}{*}{ Step 2} & Minority concentration & 0.025 & 0.013 & $1.026(0.999,1.053)$ \\
\hline & Family poverty & 0.006 & 0.031 & $1.006(0.946,1.070)$ \\
\hline & Physical disorder & 0.903 & 0.416 & $2.466(1.092,5.571)$ \\
\hline
\end{tabular}

were coded as being present or absent within the neighbourhood over the past year.

The number of births to teenage mothers in each neighbourhood and percentage of all births that were low weight (<2500 grams) in 1999 and 2000 were based on information from birth certificates. ${ }^{24}$ The index of teen births was converted to a rate per 1000 based on information from the 2000 census showing how many females aged 13 to 19 lived in each neighbourhood. ${ }^{19}$

\section{Analyses}

The reliability of the observational measure of physical disorder was evaluated in two ways. Firstly, we examined inter-rater reliability at the neighbourhood level by calculating an intraclass correlation coefficient (ICC). Next, we evaluated the internal consistency of the five items of the PDI for each neighbourhood type. ${ }^{25}$ The remaining analyses were designed to provide evidence for the validity of the index. Convergent validity was tested by correlating PDI scores with the percentage of vacant homes and neighbourhood poverty. Criterion validity was evaluated by examining the correlation between physical disorder and neighbourhood level measures of crime, firearm related injuries, teen births, and low birthweight births. Lastly, the incremental validity of the PDI was examined using hierarchical regression. Specifically, we examined whether neighbourhood physical disorder was related to year 2000 rates of crime, firearm injuries/homicides, teenage births, and low weight births, after controlling for neighbourhood poverty and minority concentration. Logistic regression was used to examine the binary outcome of firearm injuries/homicides, and linear regressions were used for all other continuous outcomes.

\section{RESULTS}

\section{Physical disorder index: reliability}

Neighbourhood level inter-rater reliability, based on the 71 neighbourhoods for which there were two independent ratings, was moderate, ${ }^{26} \quad(\mathrm{ICC}=0.64 ; 95 \% \mathrm{CI}=0.62,0.66$; $\mathrm{p}<0.001)$. Neighbourhood level internal consistency of the measure was high $(\alpha=0.90)$, and was similar in disadvantaged and non-disadvantaged neighbourhoods ( $\alpha=0.86$ and 0.91 respectively). This suggests that the reliability of the physical disorder index for the $50 \%$ block enumerated neighbourhoods is similar to those that were $100 \%$ enumerated.

\section{Physical disorder index: validity}

Physical disorder for the 82 neighbourhoods ranged from zero to 3.88 (maximum range: 0 to 5 ), with a mean of 1.99 and a standard deviation of 0.79 (see table 1). Support for the convergent validity of the physical disorder index was shown by strong correlations with the percentage of vacant homes and family poverty as measured by the census.

The PDI also showed good criterion validity and was significantly correlated with total crime, firearm related injuries and homicide, and birth statistics in 1999 and 2000. Specifically, neighbourhoods with high levels of physical disorder had higher crime rates, including firearm related homicides. Physical disorder was also positively associated with teen birth rates, as well as the percentage of low weight births within neighbourhoods.

Finally, the incremental validity of the PDI was assessed by examining its ability to account for additional variance in neighbourhood level health outcomes and crime statistics measured in 2000, after controlling for the influence of census based poverty and minority concentration. The logistic regression examining whether there was a firearm related

\begin{tabular}{|c|c|c|c|c|}
\hline & & B & SE & $95 \% \mathrm{Cl}$ \\
\hline \multicolumn{5}{|c|}{ Crime rate } \\
\hline \multirow[t]{2}{*}{ Step 1: } & Minority concentration & 0.94 & 0.36 & $(0.22,1.66)$ \\
\hline & Family poverty & 0.29 & 0.81 & $(-1.32,1.91)$ \\
\hline \multirow[t]{3}{*}{ Step 2: } & Minority concentration & 0.61 & 0.33 & $(-0.04,1.27)$ \\
\hline & Family poverty & -0.60 & 0.75 & $(-2.09,0.88)$ \\
\hline & Physical disorder & 56.05 & 11.98 & $(32.20,79.90)$ \\
\hline \multicolumn{5}{|c|}{ Teen birth rate } \\
\hline \multirow[t]{2}{*}{ Step 1: } & Minority concentration & 0.33 & 0.14 & $(0.05,0.62)$ \\
\hline & Family poverty & 1.17 & 0.32 & $(0.53,1.80)$ \\
\hline \multirow{3}{*}{ Step 2: } & Minority concentration & 0.23 & 0.14 & $(-0.04,0.50)$ \\
\hline & Family poverty & 0.89 & 0.31 & $(0.27,1.50)$ \\
\hline & Physical disorder & 17.39 & 4.96 & $(7.51,27.27)$ \\
\hline \multicolumn{5}{|c|}{ Low birth weight } \\
\hline \multirow[t]{2}{*}{ Step 1: } & Minority concentration & 0.03 & 0.03 & $(-0.03,0.10)$ \\
\hline & Family poverty & 0.14 & 0.07 & $(-0.01,0.29)$ \\
\hline \multirow[t]{3}{*}{ Step 2: } & Minority concentration & 0.03 & 0.03 & $(-0.04,0.09)$ \\
\hline & Family poverty & 0.12 & 0.08 & $(-0.27,0.28)$ \\
\hline & Physical disorder & 0.92 & 1.22 & $(-1.51,3.35)$ \\
\hline
\end{tabular}




\section{What this paper adds}

Social observations of neighbourhood disorder have been shown to relate to violent victimisation and crime, but the costs of such data collection can be substantial. This paper describes a brief, reliable, and valid ecological assessment of neighbourhood physical disorder that is related to crime, firearm injuries and deaths, and births to teenage girls, while controlling for poverty and minority concentration. This paper adds to the literature by (1) introducing a brief method for use in future research on health disparities, (2) supporting the possibility that a community's inability to realise common goals to reduce disorder and crime may also reflect an inability to realise goals to help teens make healthy choices, and (3) suggesting that interventions to increase social capital and informal social controls at the community level may not only improve safety but may also reduce socioeconomic disparities in health and wellbeing.

injury or homicide in a neighbourhood is presented in table 2. Results showed that higher levels of neighbourhood physical disorder were significantly associated with an increased risk for firearm related injury or homicide even after controlling for neighbourhood poverty and minority concentration. In fact, physical disorder was the only significant correlate of firearm injury/homicide in the final regression model.

Table 3 shows linear regressions of crime rate, teen births, and low birthweight births by neighbourhood physical disorder. For neighbourhood crime, physical disorder significantly added to the model above and beyond the influence of poverty and minority concentration. Physical disorder was the only independent variable significantly associated with increased total crime in the final model, which explained $35 \%$ of the total variance. The findings for teen births were similar, with physical disorder significantly adding to the model after controlling for the influence of poverty and minority concentration. Both physical disorder and family poverty were significantly associated with increased levels of teen births in the final model. In contrast, neighbourhood physical disorder was not significantly associated with percentage of low birthweight births after controlling for poverty and minority concentration.

\section{DISCUSSION}

In general, the findings support the reliability and validity of this brief measure of neighbourhood physical disorder based on systematic block observations. As anticipated, higher levels of physical disorder were associated with increased levels of crime, firearm injuries/homicides, and teen births, while accounting for family poverty and minority concentration. These results replicate the findings of Sampson and Raudenbush, ${ }^{8}$ who reported a similar correlation between neighbourhood disorder and census based poverty, and moderate associations between disorder and homicide, robbery, and burglary in their Chicago based study. The results extend existing research by also showing a substantial association between neighbourhood physical disorder and

\section{Implications for policy}

The results suggest that policies supporting the development of social capital and informal social controls at the community level may not only improve safety but may also reduce socioeconomic disparities in health and wellbeing. teenage birth rates that was independent of family poverty and minority concentration.

Before discussing the results of this study, some limitations need to be acknowledged. Firstly, the inter-rater reliability of the PDI was modest, most probably reflecting the different experiences of enumerators and reliability raters. City enumerators walked up to homes to inquire about potential study participants, whereas reliability raters observed physical disorder from pavements. It is feasible that there is a greater variation in physical disorder in more public spaces, such as pavements and streets, compared with spaces closer to the homes, such as on front porches. Furthermore, to make contact with members of all households, the enumerators often visited the same block repeatedly, whereas reliability raters visited each block once. Finally, although raters matched the general time of day of recordings, disagreement could have arisen from seasonal or weather variations in observations (for example, litter may have been covered by snow). Despite these differences, the index showed adequate reliability and excellent internal consistency.

Secondly, as with any cross sectional study, the direction of effects cannot be asserted. Our results indicate a direct relation between physical disorder and higher crime rates and teenage births. Based on previous neighbourhood research, the link between physical disorder and high rates of crime and teenage births may be explained by some characteristic of social networks (for example, social capital, defined variously as civic and interpersonal trust, assets and resources available via community connections, and collective efficacy). ${ }^{27-29}$ Alternatively, the link may show that higher risk people (for example, vulnerable teenagers, perpetrators of crime) self select into disordered neighbourhoods. Longitudinal research, which includes individual level factors, is clearly needed to clarify the temporal ordering of these effects and to identify the relevance of different social mechanisms.

Reinforcing the notion that crime and population health may share similar social origins, ${ }^{30}$ observable signs of physical disorder were related to higher levels of poverty, crime and gun violence, and also to births to teenage girls, independent of poverty and minority concentration. Neighbourhood economic disadvantage has been shown to predict lower levels of collective efficacy, which in turn, predicts higher levels of disorder and crime. ${ }^{8}$ This paper supports the possibility that a community's inability to realise common goals to reduce disorder and crime may also reflect an inability to realise goals to help teens make healthy choices. A relation between neighbourhood disorder and health outcomes related to sexual behaviour was found by Cohen and colleagues, ${ }^{15}$ in their study of neighbourhood deterioration and gonorrhoea rates. Our paper also supports the possibility that disorder may relate to unhealthy choices by increasing one's general sense of powerlessness. ${ }^{31}$

At the simplest level, reductions in physical disorder may be associated with lower rates of crime and adverse health outcomes. To the extent that conditions such as litter, vandalism, and abandoned cars are an outward sign of poor collective efficacy however, these results also have important implications for a range of community based prevention efforts and policy. They suggest that policies supporting the development of social capital and cohesion at the community level may not only improve safety but may also reduce socioeconomic disparities in health and wellbeing. Social ties with neighbours have been found to buffer the effects of perceived neighbourhood disorder on fear and mistrust, ${ }^{32}$ suggesting that the relation between disorder on negative health outcomes may be mitigated by improving neighbourhood cohesion. Increasing social connections can result in more sharing among neighbours of information regarding 
public health issues, resources and services, and raise collective support for health promoting behaviours. Areas plagued by physical disorder may be communities that will benefit most from the efforts of crime prevention and public health practitioners. Minimally, neighbourhoods with high physical disorder may benefit from targeted teen pregnancy prevention efforts.

\section{ACKNOWLEDGEMENTS}

It is with deep sadness and regret that we report the death of Evelyn Wei, the lead author on this paper. Evelyn was a valued colleague and friend and we miss her dearly. This paper would not have been possible without the hard work of the enumerators, the data entry staff, and Geoffrey Barnes, PhD and Rebecca Shue for the programming and data management. Brandi Rosselli, policy analyst for the department of city planning, provided the neighbourhood level 2000 census data. Deborah Friedman, PhD, provided the neighbourhood level Allegheny County Injury Surveillance System (ACISS) data. John Kokenda, statistical analyst, and Deidre Hennon, chief of biostatistics, provided the neighbourhood level birth statistics from the Allegheny County Health Department. The Pennsylvania department of health specifically disclaims responsibility for any analyses, interpretations, or conclusions.

\section{Authors' affiliations}

E Wei, Late of the Western Psychiatric Institute and Clinic, University of Pittsburgh, Pittsburgh, Pennsylvania, USA

A Hipwell, D Pardini, R Loeber, Western Psychiatric Institute and Clinic, University of Pittsburgh

J M Beyers, Casey Family Programs, Seattle, State of Washington, USA

Funding: preparation of this article was supported in part by grants from the National Institute of Mental Health (MH56630) and the National Institute of Drug Abuse (DA12237). Points of view or opinions in this article are those of the authors and do not necessarily represent the official position or policies of the National Institute of Mental Health or the National Institute of Drug Abuse.

Conflicts of interest: none.

Ethics approval: there were no human subjects involved in the data collection for the purpose of the study described in this article. However, The Institutional Review Board at the University of Pittsburgh approved all protocols for the large scale study of which this data collection effort was a part.

\section{REFERENCES}

1 Sampson RJ, Groves WB. Community structure and crime: testing socialdisorganization theory. American Journal of Sociology 1989;94:774-802.

2 Sampson RJ, Raudenbush SW, Earls F. Neighborhoods and violent crime: a multilevel study of collective efficacy. Science 1997;277:918-24.

3 Aneshensel CS, Sucoff CA. The neighborhood context of adolescent mental health. J Health Soc Behav 1996;37:293-310.

4 Beyers JM, Bates JE, Pettit GS, et al. Neighborhood structure, parenting processes, and the development of youths' externalizing behaviors: a multilevel analysis. Am J Community Psychol 2003;31:35-53.
5 Leventhal T, Brooks-Gunn J. The neighborhoods they live in: the effects of neighborhood residence on child and adolescent outcomes. Psychol Bull 2000;126:309-37.

6 Raudenbush SW, Sampson RJ. Ecometrics: toward a science of assessing ecological settings with application to the systematic social observation of neighborhoods. Sociol Methodol 1999;29:1-41.

7 Wilson JQ, Kelling G. The police and neighborhood safety: broken windows. Atlantic Month 1982;127:29-38.

8 Sampson RJ, Raudenbush SW. Systematic social observation of public spaces: a new look at disorder in urban neighborhoods. Am J Sociol 1999; 105:603-51.

9 Perkins DD, Taylor RB. Ecological assessments of community disorder: their relationship to fear of crime and theoretical implications. Am J Community Psychol 1996;24:63-107.

10 Sampson RJ, Morenoff JD, Gannon-Rowley T. Assessing 'neighborhood effects': social processes and new directions in research. Annu Rev Sociol 2002;28:443-78.

11 Diez-Roux AV. Investigating neighborhood and area effects on health. Am J Public Health 2001;91:1783-9.

12 Winkleby MA, Cubbin C. Influence of individual and neighbourhood socioeconomic status on mortality among black, Mexican-American, and white women and men in the United States. J Epidemiol Community Health 2003;57:444-52.

13 Cubbin C, LeClere FB, Smith GS. Socioeconomic status and injury mortality: individual and neighbourhood determinants. J Epidemiol Community Health 2000;54:517-24.

14 Pearl M, Braveman P, Abrams B. The relationship of neighborhood socioeconomic characteristics to birthweight among 5 ethnic groups in California. Am J Public Health 2001;91:1808-14.

15 Cohen D, Spear S, Scribner R, et al. "Broken windows" and the risk of gonorrhea. Am J Public Health 2000;90:230-6.

16 Hipwell $A E$, Loeber R, Stouthamer-Loeber $M$, et al. Characteristics of girls with early onset disruptive and antisocial behaviour. Crim Behav Ment Health 2002;12:99-118.

17 US Census Bureau. 1990 Census of population and housing: summary tape file 3A. Washington, DC: Department of Commerce, 1992.

18 Department of City Planning. 2000 Neighborhood census data. Pittsburgh, PA: City of Pittsburgh, 2003.

19 US Census Bureau. Census 2000 summary file 3-United States. Washington, DC: Department of Commerce, 2002.

20 Federal Bureau of Investigation. Uniform crime reports. Washington, DC: US Department of Justice, 2000.

21 Federal Bureau of Investigation. Uniform crime reports. Washington, DC: US Department of Justice, 2001.

22 Friedman DI, Coben JH. Firearm injuries and fatalities in Allegheny County, PA, 1999. Pittsburgh, PA: Allegheny County Health Department, 2000.

23 Friedman DI, Coben JH. Firearm injuries and fatalities in Allegheny County, PA, 2000. Pittsburgh, PA: Allegheny County Health Department, 2001.

24 Office of Biostatistics. Allegheny County birth statistics. Pittsburgh, PA: Allegheny County Health Department, 2002.

25 Cronbach $\amalg$. Essentials of psychological testing. 3rd ed. New York: Harper and Row, 1970.

26 Cicchetti DV. Guidelines, criteria, and rules of thumb for evaluating normed and standardized assessment instruments for psychology. Psychol Assess 1994;6:284-90.

27 Macinko J, Starfield B. The utility of social capital in research on health determinants. Milbank Q 2001;79:387-427.

28 Portes A. Social capital: its origins and application in modern sociology. Annu Rev Sociol 1998;24:1-24.

29 Kawachi I, Berkman, L. Social cohesion, social capital and health. In: Social epidemiology. London: Oxford University Press, 2000:174-90.

30 Kawachi I, Kennedy BP, Wilkinson RG. Crime: social disorganization and relative deprivation. Soc Sci Med 1999;48:719-31.

31 Geis KJ, Ross CE. A new look at urban alienation: the effect of neighborhood disorder on perceived powerlessness. Soc Psychol Q 1998;61:232-46.

32 Ross CE, Jang SJ. Neighborhood disorder, fear, and mistrust: the buffering role of social ties with neighbors. Am J Community Psychol 2000;28:401-20. 